\title{
Embodying Okhotsk Ethnicity: Human Skeletal Remains from the Aonae Dune Site, Okushiri Island, Hokkaido
}

\author{
(2) (0) (0) \\ HIROFUMI MATSUMURA, MARK J. HUDSON, \\ KENICHIRO KOSHIDA, AND YOICHI MINAKAWA
}

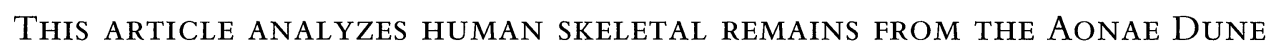
site on Okushiri Island, Hokkaido, in the context of three major areas of debate in recent archaeology. These areas of debate are renewed interest in the archaeology of ethnicity (e.g., Emberling 1997; Jones 1997), growing controversy over the relationship between biology, language, and culture in prehistory (e.g., Bellwood 1996; Bellwood and Renfrew 2003; Hudson 1999; Kirch and Green 2001; Terrell 2001), and continued interest in the forensic classification of individual skeletal remains, newly stimulated in the United States by the legal problems surrounding the Native American Graves Protection and Repatriation Act (NAGPRA) (e.g., Ousley 2001; Rose et al. 1996). The Aonae Dune site, which is described in more detail below, belongs to the Okhotsk culture that occupied the northern and eastern coastal fringes of Hokkaido between about A.D. 550 and 1200 (Hudson 2004; Ohyi 1975; Yamaura 1998). In many respects the Hokkaido Okhotsk appears to come close to the classic definition of an archaeological culture, its separate and distinctive material remains apparently overlapping with a biological population that was morphologically different from the Ainoid populations that inhabited the rest of Hokkaido (Ishida 1988, 1994). Given their origins outside Hokkaido, the Okhotsk people presumably also had a separate language or languages. ${ }^{1}$ Despite evidence for contact with neighboring Epi-Jōmon groups known from harpoon (Maeda 2002) and ceramic technology (Hall et al. 2002), as an archaeological culture the Hokkaido Okhotsk appears to have remained largely separate from other groups until its final Tobinitai stage (Table 1).

At the outset of this article it is important to explain how we approach the relationship between ethnicity and human biology. Despite our focus here on human skeletal remains, we are not suggesting that ethnicity can be reduced to

Hirofumi Matsumura is an associate professor in the Department of Anatomy, Sapporo Medical University. Mark J. Hudson is an associate professor in the Institute of History and Anthropology, University of Tsukuba. Kenichiro Koshida is an archaeologist with the Hokkaido Prefectural Board of Education. Yoichi Minakawa is an archaeologist at the Hokkaido Prefectural Archaeological Operations Center.

Asian Perspectives, Vol. 45, No. 1 (C) 2006 by the University of Hawai'i Press. 
Table i. Cultural Phases in Late Prehistoric Hokkaido

\begin{tabular}{lll}
\hline APPROXIMATE DATES & SEA OF OKHOTSK COASTLINE & SOUTH AND WEST HOKKAIDO \\
\hline $1600-1869$ & Classic Ainu & Classic Ainu \\
$1200-1600$ & Formative Ainu & Formative Ainu \\
$1000-1200$ & Final Okhotsk (Tobinitai) & Late Satsumon \\
$800-1000$ & Late Okhotsk & Middle Satsumon \\
$550-800$ & Early Okhotsk & Epi-Jōmon/Early Satsumon \\
100 B.C.-A.D. 550 & Epi-Jōmon \& Susuya & Epi-Jōmon \\
\hline
\end{tabular}

biology. Ethnicity is a constructed, cultural phenomenon. An ethnic group can be defined as "a self-perceived group of people who hold in common a set of traditions not shared by the others with whom they are in contact" (DeVos 1982:9), a definition that is useful because it emphasizes the role of contact rather than isolation in the formation of ethnic identities. Furthermore, we do not start with the assumption that the biological, cultural, and linguistic elements of the Okhotsk necessarily overlapped. As noted by Evison (2001) and others, the extent of such overlap is historically contingent and needs to be the focus of study. The broader theoretical point that we wish to make here, however, is that since biology forms one important aspect of human identities, the study of human biology can help us understand the process of ethnic construction in the past. In other words, cases where we can actually demonstrate that biology and culture did not overlap require our attention as anthropological archaeologists precisely because they show the complex, constructed nature of ethnicity.

One example of the interplay between biology and culture in the construction of ethnicity is the Northern Fujiwara family who ruled over northern Honshu in the twelfth century A.D. Although in contemporary texts the Northern Fujiwara followed earlier chieftains in the region in referring to themselves as "Emishi," or non-Japanese "Eastern Barbarians" (Batten 2003:107), analyses of the mummies of the Northern Fujiwara chiefs has shown that they were biologically similar to early medieval Japanese populations of the Kyoto region (Hanihara 1998). The interpretation of such results is, of course, by no means simple. Employing the definition of ethnicity used by most cultural anthropologists and sociologists, the Northern Fujiwara chiefs would probably be classified as Emishi on the grounds that this was how they perceived themselves - although in this case the precise meaning of the term "Emishi" is unclear (cf. Batten 2003:102-107). Other similar examples can be just as complex. Ousley (2001) discusses several cases of disparity between biological and cultural identity discovered during NAGPRA repatriation work at the Smithsonian Institution. In one case, a skeleton of a "Sioux full-blood" acquired by the Smithsonian in 1904 was shown to be a white male who had participated in Wild West sideshows. In another, an "Indian" skeleton, which was nicknamed the "Kiowa Horse Thief," was shown to be a EuropeanAmerican who had probably been kidnapped by the Kiowa as a child. While such cases may be legally problematic in terms of NAGPRA, they were probably not uncommon in the past. Hunter-gatherer ethnographies demonstrate many situations where individuals from other groups are incorporated into a particular society. Those situations include resource stress, warfare, and personal disagree- 
ments. Examples of this process can be seen in Russian ethnographer Lev Shternberg's work on the Nivkh (Gilyak) of Sakhalin Island. As Dolukhanov (2003:179) notes, "Shternberg cites numerous cases, when Nivkh individuals escaping persecution and failure, quit their paternal tribe seeking refuge in neighboring alien groups. They became adopted, and, having married usually a widowed woman acquired the language and habits of the adoptive tribe." Similar examples could be quoted from many other regions of the world.

Although, as noted already, Okhotsk archaeological remains in Hokkaido give the impression of a relatively separate and integrated cultural unit, given the reproductive and other social demands of a linear, coastal settlement pattern we would not expect the Okhotsk people to be totally isolated from neighboring populations. Ishida (1988) has already reported a partially preserved cranium from the Okhotsk site of Menashi-domari that shares morphological features with the Ainu. Here we report new skeletal remains that are culturally Okhotsk but morphologically very different from most Okhotsk individuals. What follows in the main body of this article is a necessarily technical analysis of the human skeletal remains from the Aonae Dune site. In the discussion section we then return to the difficult question of how the biological identities of the three Aonae individuals discussed may have related to the broader context of Okhotsk ethnicity, and then we touch briefly upon the question of scale in the study of prehistoric ethnicity.

\section{MATERIALS AND METHODS}

The Aonae Dune site is located on the southern coast of Okushiri, a small (142.94 $\mathrm{km}^{2}$ ) island $18 \mathrm{~km}$ off the coast of southwestern Hokkaido (Fig. 1). Small-scale excavations in 2001-2002 to investigate the nature and extent of the site were conducted by the Hokkaido Prefectural Archaeological Operations Center under the direction of Koshida (Hokkaido Prefectural Archaeological Operations Center 2002, 2003). A total area of $90 \mathrm{~m}^{2}$ was opened in several test trenches. The site is located on a sand dune that has maximum dimensions of $400 \mathrm{~m}$ in length, $70 \mathrm{~m}$ in width, and $9.8 \mathrm{~m}$ in height. Radiocarbon dates from the site are shown in Table 2 .

Three human skeletons were discovered during the excavations at Aonae. Skeleton No. 1 was an extended adult burial with the head oriented northwest. Skeletons No. 2 and 3 were found in the north section wall of the excavation trench; although only the crania were recovered from these individuals, it is not clear if postcranial materials remain within the unexcavated area.

Skeleton No. 1 is a direct pit inhumation found inside an earlier Okhotsk pit building, H-2 (Fig. 2). The pit for the burial was cut from Layer XI and thus predates the tenth-century A.D. Mt. Paektu-Tomakomai tephra identified in Layer IX. The grave goods comprised an iron knife and a bone disk (Fig. 2). The knife was found on the right forearm and has a remaining length of $5.65 \mathrm{~cm}$. The disk is made of whale bone and has a diameter of $4.7 \mathrm{~cm}$. It is perforated by a $0.8-\mathrm{cm}$ hole in the center. This type of disk was used by the Kuril Ainu until historic times and is usually termed a kukkurukesh in Hokkaido archaeology. Such disks are not known from Satsumon contexts but have been found at a number of Okhotsk sites, although this is only the second example from a burial. Thus, al- 

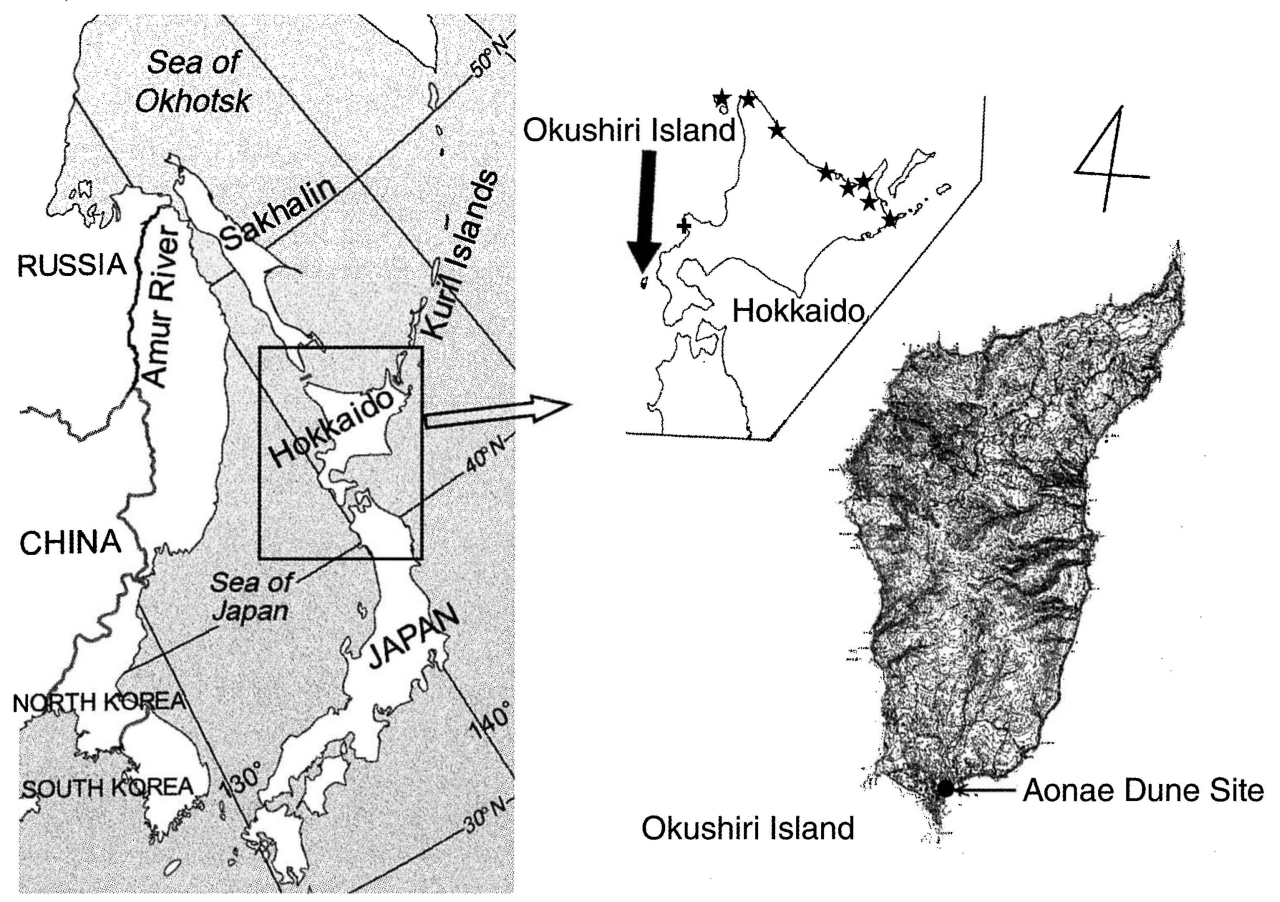

Fig. 1. Location of the Aonae Dune Site on Okushiri Island and representative Okhotsk culture sites $(\star)$ and the Chatsu 4 site (+) discussed in this article.

Table 2. Radiocarbon Dates from the Aonae Dune Site

\begin{tabular}{|c|c|c|c|c|}
\hline LAB NO. & LOCATION & MATERIAL & ${ }^{14}$ C DATE (B.P.) & $\begin{array}{l}\text { CALIBRATED DATE } \\
\text { (I SIGMA) }\end{array}$ \\
\hline Beta-164480 & Floor of $\mathrm{H}-1$ & Charcoal & $1770+40$ & A.D. $230-330$ \\
\hline Beta-164481 & Floor of $\mathrm{H}-1$ & $\begin{array}{l}\text { Carbonized accretion } \\
\text { on pottery }\end{array}$ & $2210+40$ & 370-200 в.С. \\
\hline Beta-164482 & Grid E14-N13 & Charcoal & $1780+40$ & A.D. $220-260$ \\
\hline Beta-174461 & Floor of $\mathrm{H}-2$ & Carbonized walnut & $1580+40$ & A.D. $420-540$ \\
\hline Beta-174462 & Floor of $\mathrm{H}-3$ & Charcoal & $1590+40$ & A.D. $420-530$ \\
\hline
\end{tabular}

though Aonae is located outside of the main area of Okhotsk settlement (see Fig. 1), the stratigraphy, grave goods, and northwest orientation of this burial allow us to be reasonably certain that this individual belonged to the Okhotsk culture. A consideration of the overall stratigraphy suggests that the late seventh or eighth century is the most probable date for this burial.

Skeletons No. 2 and 3 were two subadult skulls found facing each other at the bottom of the mid-seventh century Okhotsk pit building H-3. There is no evidence for a burial pit and it seems the bodies were placed in the house pit soon after abandonment, perhaps being covered with a thin layer of sand. Stratigraphically, it is not clear if these individuals were both buried at the same time. The 


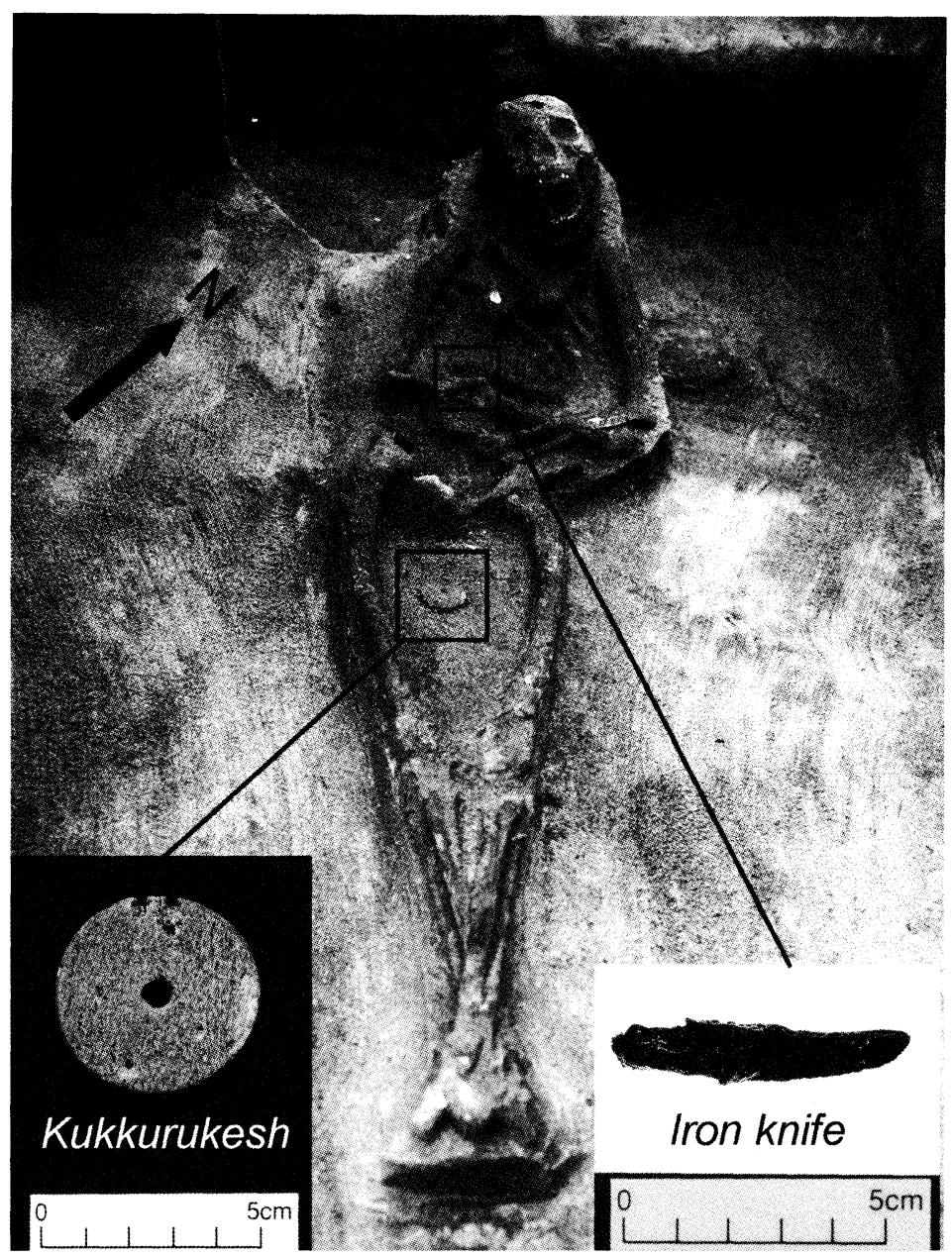

Fig. 2. The burial of Aonae Dune skeleton No. 1 with artifacts (iron knife and kukkurukesh bone disk). N: North.

heads were oriented southeast, 180 degrees opposite to Skeleton No. 1. A pounding stone and a pebble were placed to the left and right of the cranium of Skeleton No. 2, an arrangement that is similar to Epi-Jōmon burials of the Hokudai phase. The base of an Okhotsk pot, a jasper bead, stone flakes, sea lion bones, and abalone and sea urchin shells were found close to the skulls and are possibly associated, or at least contemporary, with the burials.

In this article, we first describe the preservation and morphology of the Aonae Dune skeletons with the results of age estimations and sex identifications, then analyze the cranial and dental measurement data. Skeletal measurements were taken following Martin's definitions (Martin and Saller 1957). Some cranial measurements are estimated by doubling the measurement taken from one side of the skull because the other side is incomplete. The maximum cranial length of Skeleton No. 1 was measured before the glabella region was damaged during reconstruction. Facial flatness measurements and indices follow Yamaguchi (1973). 
Dental crown measurements comprising mesiodistal (MD) and buccolingual (BL) diameters were recorded after Moorrees and Reed (1954), which were taken as the greatest dimensions of crowns. The degree of occlusal wear on the crown surface was recorded according to Broca's grading system (Martin and Saller 1957). Nonmetric tooth traits were scored according to the ASU plaques of Turner et al. (1991) for permanent dentition and those of the "D" series (Hanihara 1961) for deciduous dentition. The nonmetric as well as metric traits were recorded from the better-preserved and less worn side. The standard used to estimate dental age for the child skeletons was Ubelaker (1991). Sex determination is difficult for subadult specimens based on skeletal morphology. Therefore, in cases where permanent teeth were present in subadult specimens, discriminant function analysis for sexing was performed using dental metric data taken from the Hokkido Ainu and ancient Japanese samples by the first author. To estimate the stature of the adult skeleton, Fujii's (1960) formula was adopted, using maximum femoral length.

Next, in order to disclose affinities with other prehistoric and historic populations of Hokkaido, we undertook morphometric analyses using cranial and dental measurements. Because dental measurements were not recorded from the adult Skeleton No. 1 due to heavy attrition, only cranial metrics were used for the statistical analysis. On the other hand, cranial metrics were not used from the two subadult skeletons, tooth crown measurements recorded from the only slightly worn permanent dentition of Skeleton No. 2 and the deciduous teeth of Skeleton No. 3 being used for the analysis. In order to visually display the resemblance or dissimilarity to group averages of the comparative population samples given below, deviation diagrams were drawn using the standardized cranial or dental measurements and the results compared between the Aonae Dune individuals and the others. Furthermore, to estimate the morphological affinities of these Aonae Dune skulls and dentition to comparative samples, Penrose's shape distances (Penrose 1954) and Q-mode correlation coefficients (Sneath and Sokal 1973) were calculated using the measurement data. Both procedures indicate likelihoods of similarity in proportion or shape of the cranial and dental morphology between the samples, techniques which have been commonly used to assess population affinity in physical anthropology.

In the comparison of dental metrics, only the mesiodistal diameters were utilized because they tend to be more suggestive of phylogenetic relationships than buccolingual diameters (Matsumura 1989). For comparative cranial metric data, as contemporary Satsumon remains are extremely rare, we used female averages of cranial measurements from ancestral Epi-Jōmon populations of Hokkaido (Dodo and Kawakubo 2002) and their descendants, the Hokkaido Ainu (Koganei 1893; Yamaguchi 1973), as well as Okhotsk samples from the Omisaki site in northern Hokkaido (Ishida 1988). In order to test similarity to contemporary Honshu Japanese as well as the above representative Hokkaido samples, data of the protohistoric Kofun population from the Kanto region in central Honshu (Yamaguchi 1987), which is chronologically parallel to the Satsumon period in Hokkaido, were added. The crown measurement data of the permanent teeth recorded from the above comparative population samples are cited from Matsumura $(1990,1993,1994)$. Since data on deciduous tooth size are not recorded for the Epi-Jōmon series, data from Jōmon samples (Matsumura 1991) were substituted. For the Okhotsk deciduous teeth, data recorded from the Hamanaka site 
on Rebun Island were cited from Ishida and Hanihara (1992). Deciduous tooth size comparisons were performed using combined data from both sexes since all recorded comparative data were taken from unknown sex samples. A comparison using nonmetric dental traits taken from the Aonae Dune individuals was not made because such comparisons need frequency data based on a large sample size.

\section{SKELETAL PRESERVATION AND MORPHOLOGY}

\section{Skeleton No. 1}

Cranium - This skeleton is an adult female (Fig. 3). The cranium was poorly preserved and the bone very brittle. The right side of the frontal, the right malar bone, the nasal bone, and both zygomatic arches were missing, but the cranium could be reconstructed. It is clear from the pelvis that this was a female (see below), and this conclusion is supported by cranial features such as the small mastoid processes, perpendicular frontal bone, the near absence of supraorbital ridges, weakly defined occipital torus, and smooth nuchal plane. This cranium is small, gracile, and typically female. The sagittal suture is fused on the outer surface and the tooth crown surfaces are heavily worn (Broca's third grade), leading us to conclude that the age of this individual can be estimated as middle aged (35-49 years).

The facial skeleton is characterized by a quite flat glabella region (observed before this portion was damaged) and nasal root, rectangular orbital margins, zygomatic bones that do not project laterally, deeply depressed cheeks around the zygomaxillary suture, a wide nasal opening, edge-to-edge bite at the incisor occlusions, and relatively low facial height. These features are shared with EpiJōmon females that are known from Hokkaido and are clearly different from other known Okhotsk populations. Only the flat glabella region is unlike that of Epi-Jōmon crania, which often have prominent glabellae, but when we consider that this was a female, there is no difficulty in including this feature within the range of Epi-Jōmon variability.

In the anterior view, the forehead is narrow and the frontal eminence is weak. The superciliary arches are flat. The nasal root is not depressed. The tops of the frontal processes of the maxillae are oriented slightly transversally at the frontomaxillary suture. The superior orbital margins are slightly rounded, but the inferior lines are straight. The orbital shape is nearly rectangular and declines slightly toward the lateral inferior direction. The orbital heights are moderate. The presence of frontal notches or supraorbital foramina is unknown because these areas of the frontal bone are missing. The subnasal region is weakly depressed. The lateral expansion of the malar bones is not prominent and the maxillary alveolar processes are small.

In the lateral view, the frontal bone is perpendicularly elevated, and the frontal medial line is strongly concave. The temporal lines are not distinct, suggesting weak temporal muscles. The supramastoid crests are also not prominent. The mastoid processes are quite small. The external acoustic meatus openings have an elliptical shape. The infratemporal crests are not sharp. The prominence of the anterior nasal spine is unknown as this portion is broken.

The external occipital protuberance is weakly developed. The superior nuchal line is clear, but the inferior line is not distinct. The nuchal plane is smooth. The 


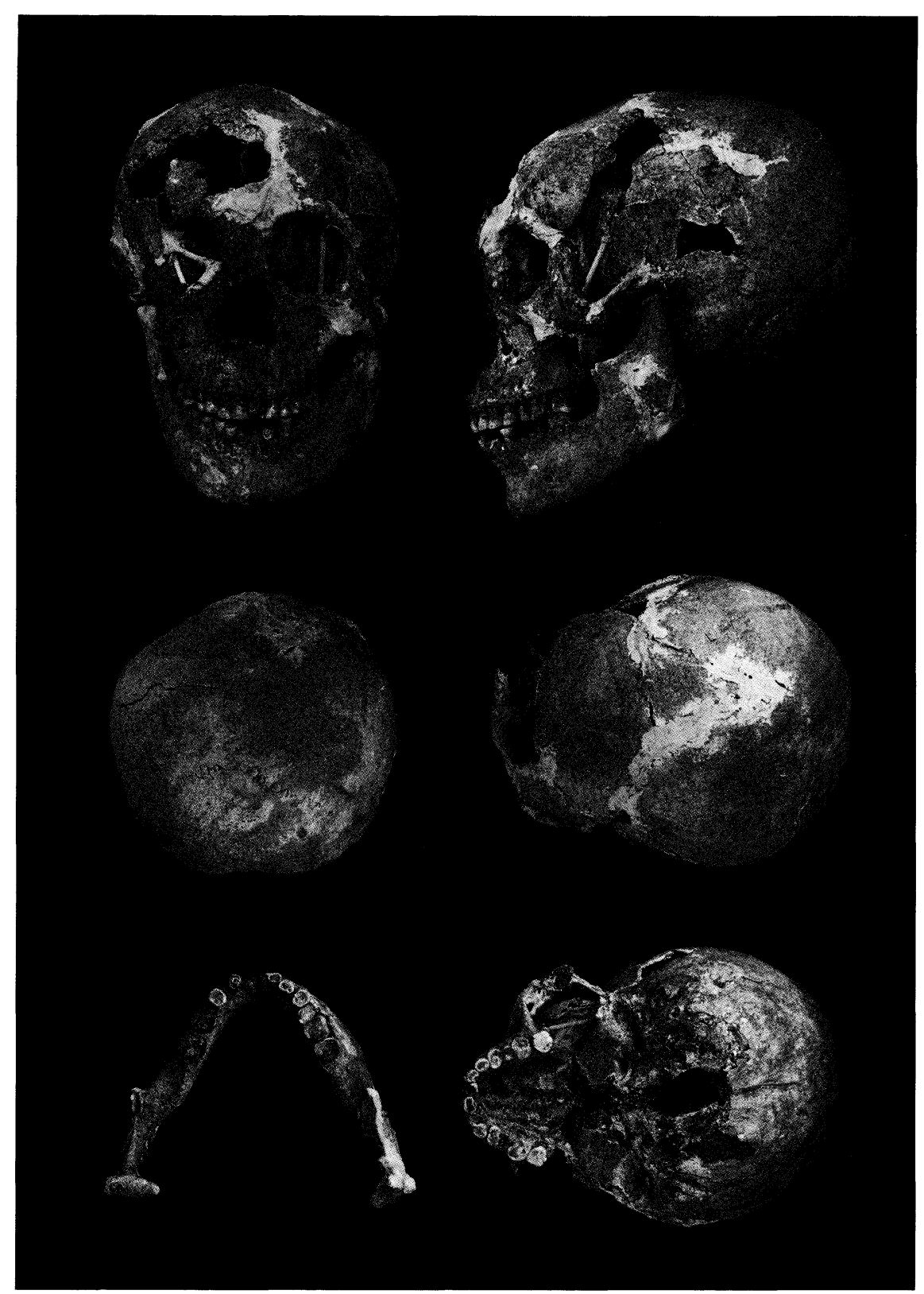

Fig. 3. Various views of the skull of Aonae Dune skeleton No. 1 (adult female).

transverse occipital suture vestige is absent. On the outer surfaces in the superior view, the coronal and lambdoidal sutures are partially fused, while the sagittal suture is fully fused. The condition of these sutures on the inner surface is unknown because the fragile inner vault became cemented with soil when applying a chemical binder in the field. 
Table 3. Preservation for the Permanent and Deciduous Teeth of Three Individuals from the Aonae Dune Site (I: Incisor, C: Canine, P: Premolar, M: Molar, D: Deciduous, X: Tooth Not Erupted, O: Tooth Missing But Socket Present, /: Вотн Toоth And Socket Missing)

\begin{tabular}{|c|c|c|c|c|c|c|c|c|c|c|c|c|c|c|c|}
\hline \multirow[b]{2}{*}{ Skeleton No. 1} & \multicolumn{7}{|c|}{ LEFT SIDE } & \multicolumn{8}{|c|}{ RIGHT SIDE } \\
\hline & & & & & & & & & & & & & & & \\
\hline Maxillary & $\mathrm{X} \quad \mathrm{M} 2$ & M1 & P2 & P1 & $\mathrm{C}$ & I2 & I1 & I1 & $\mathrm{I} 2$ & C & P1 & P2 & M1 & M2 & $\mathrm{X}$ \\
\hline Mandibular & $\mathrm{X} \quad \mathrm{M} 2$ & M1 & P2 & P1 & $\mathrm{C}$ & I2 & I1 & $\mathrm{O}$ & $\mathrm{O}$ & C & P1 & $\mathrm{O}$ & M1 & M2 & $\mathrm{X}$ \\
\hline \multicolumn{16}{|l|}{ Skeleton No. 2} \\
\hline Maxillary & & M1 & $\operatorname{dm} 2$ & P1 & C & I2 & I1 & I1 & I2 & C & P1 & $\mathrm{dm} 2$ & M1 & & \\
\hline \multirow[t]{2}{*}{ Mandibular } & & M1 & & P1 & $\mathrm{C}$ & $\mathrm{I} 2$ & I1 & I1 & I2 & $\mathrm{C}$ & $\mathrm{P} 1$ & P2 & M1 & & \\
\hline & (Maxilla & ary an & $\mathrm{d} \operatorname{man}$ & dibula & M2 & and & M3 & are $f$ & orme & $\mathrm{d}$ in & the jay & & & & \\
\hline Skeleton No. 3 & & & & & & & & & & & & & & & \\
\hline Maxillary & & M1 & $\mathrm{dm} 2$ & $\mathrm{dm} 1$ & $\mathrm{dc}$ & / & di1 & / & di 2 & $\mathrm{dc}$ & $\mathrm{dm} 1$ & $\operatorname{dm} 2$ & M1 & & \\
\hline Mandibular & & M1 & $\operatorname{dm} 2$ & / & $\mathrm{O}$ & $\mathrm{O}$ & $\mathrm{O}$ & $\mathrm{O}$ & $\mathrm{O}$ & $\mathrm{O}$ & $\mathrm{dm} 1$ & $\mathrm{dm} 2$ & M1 & & \\
\hline
\end{tabular}

The mandible is nearly complete. The mental symphysis is quite prominent and the chin height is also rather high. However, the mental tubercle and mental spine are not prominent. The width of the ramus is moderate and it is inclined posteriorly, displaying a rectangular shape. The mandibular notch and pre-angle incision are shallow. The angle does not bend laterally. The baseline of the body is flat. The muscle attachment surfaces are also not well developed. The body is gracile and typically female.

Skeletal measurements and facial flatness measurements and indices are given in Table 4.

The teeth listed in Table 3 were associated with this individual. The crown surfaces are very worn. The anterior teeth attrition reaches Broca's third level. The posterior teeth are more heavily worn and lack crown surfaces (Broca's fourth level). Any third molars are not erupted. There is no room for third molars in the maxillary alveolar process behind the distal area of the second molars, indicating that the upper third molars are congenitally absent. For the lower third molars, without X-ray observation it is not clear whether they are also congenitally absent. The absence of enamel contact wear at the distal ends of the second molars is not consistent with the possibility of antemortem loss of the third molars. The alveolar sockets of the right maxillary and mandibular molars are severely eroded on both sides by alveolar abscesses that have exposed the lingual molar roots (Fig. 4). No carious lesions or calculus deposits were observed. Dental crown measurements comprising mesiodistal (MD) and buccolingual (BL) diameters are presented in Table 5 . As given in Table 6, many nonmetric traits were not scored due to heavy attrition. As far as the scored traits are concerned, no distinctive characteristics were found.

Postcranial Remains - Postcranial preservation was poor and fragmentary. Although the scapulae, humeri, and forearm bones were observed when the burial was excavated, they proved extremely brittle upon removal from the ground and it was not possible to reconstruct any of these bones. As far as could be observed, no unusual features were present. Some parts of the ilia were preserved but were 
Table 4. Cranial Measurements and Indices of Aonae Dune Skeleton No. I

\begin{tabular}{|c|c|c|c|c|c|}
\hline M & MEASUREMENT & & M & MEASUREMENT & \\
\hline 1. & Maximum cranial length & 176 & 54. & Nasal breadth & 28 \\
\hline 5. & Basion-nasion length & $(102)$ & 55. & Nasal height & 46 \\
\hline 8. & Maximum cranial breadth & 142 & 60. & Alveolar length & 44 \\
\hline $8: 1$ & Cranial index & 80.7 & 61. & Alveolar breadth & 62 \\
\hline 10. & Maximum frontal breadth & $(98)$ & 62. & Internal palate length & 48 \\
\hline 17. & Basion-bregma height & $(130)$ & 63. & Internal palate breadth & 39 \\
\hline 23. & Horizontal circumference & 510 & 65. & Bicondyler breadth & 115 \\
\hline 24. & Transverse arc & 334 & 66. & Bigonial breadth & 104 \\
\hline 25. & Sagittal arc & 355 & 68. & Mandibular length & 75 \\
\hline 26. & Frontal arc & 122 & 69. & Symphyseal height & 32 \\
\hline 27. & Parietal arc & 119 & $69 .(3)$ & Mand. body breadth & 13 \\
\hline 28. & Occipital arc & 114 & 70 & Ramus height & 53 \\
\hline 40. & Basion-prosthion breadth & $(98)$ & 71. & Ramus breadth & 34 \\
\hline 43. & Upper facial breadth & 102 & & Frontal chord & 98.0 \\
\hline 45. & Bizygomatic breadth & $(138)$ & & Frontal subtense & 14.1 \\
\hline 46. & Bimaxillary breadth & 94 & & Frontal index & 14.4 \\
\hline 48. & Upper facial height & 64 & & Zygomaxillary chord & 98.0 \\
\hline $48: 46$ & Upper facial index (Virchow) & 68.1 & & Zygomaxillary subtense & 25.0 \\
\hline 51. & Orbital breadth & 40 & & Zygomaxillary index & 25.5 \\
\hline 52. & Orbital height & 33 & & & \\
\hline
\end{tabular}

M: Martin's number (Martin and Saller 1957); estimated values by half side in parentheses.
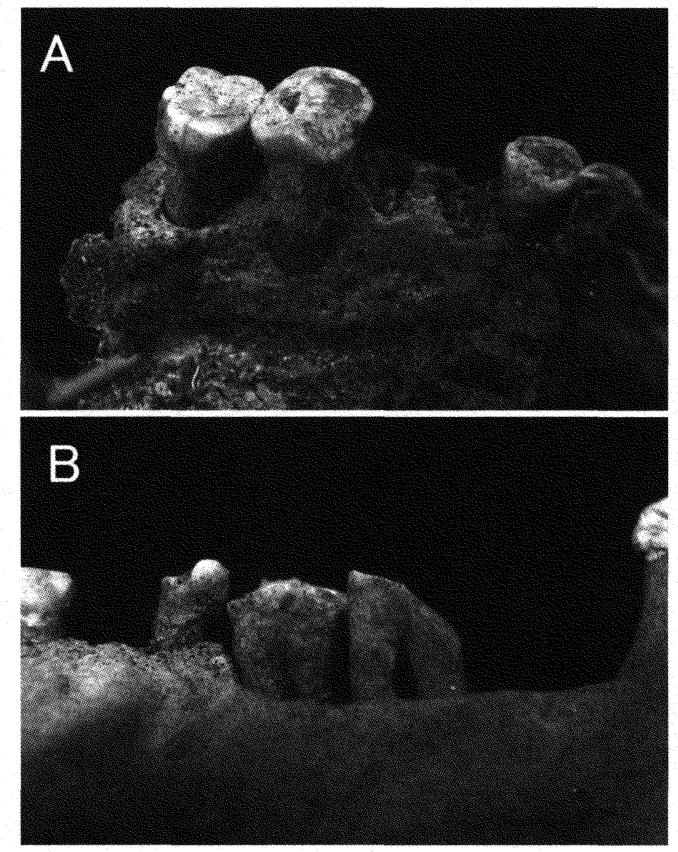

Fig. 4. Dental abscesses observed at the lingual sides of the right maxillary molars (A) and mandibular molars (B) of the Aonae Dune No. 1 skeleton. 
Table 5. Mesiodistal (MD) and Buccolingual (BL) Crown Diameters (MM) of the Aonae Dune Dentition

\begin{tabular}{|c|c|c|c|c|c|c|c|c|c|c|}
\hline \multicolumn{3}{|c|}{ NO. I ADULT FEMALE } & \multicolumn{4}{|c|}{ NO. 2 CHILD } & \multicolumn{4}{|c|}{ NO. 3 CHILD } \\
\hline $\begin{array}{l}\text { Tooth } \\
\text { Maxillary }\end{array}$ & Side & $\mathrm{BL}$ & Tooth & Side & MD & $\mathrm{BL}$ & Tooth & Side & $\mathrm{MD}$ & $\mathrm{BL}$ \\
\hline I1 & left & 6.52 & I1 & left & 8.27 & 7.43 & di1 & right & 6.58 & \\
\hline I2 & left & 5.71 & I2 & left & 7.36 & 6.21 & di2 & right & 5.57 & 4.69 \\
\hline $\mathrm{C}$ & left & 6.69 & $\mathrm{C}$ & left & 8.00 & 8.59 & $\mathrm{dc}$ & right & 6.64 & 5.07 \\
\hline P1 & left & 9.36 & P1 & left & 6.97 & 9.05 & $\mathrm{dm} 1$ & right & 7.01 & 8.04 \\
\hline P2 & & & P2 & & & & $\mathrm{dm} 2$ & right & 8.88 & 9.80 \\
\hline M1 & right & 10.85 & M1 & left & 10.90 & 12.56 & M1 & right & 10.09 & 11.44 \\
\hline M2 & right & 10.03 & M2 & left & 9.39 & 11.37 & & & & \\
\hline \multicolumn{11}{|c|}{ Mandibular } \\
\hline I1 & & & I1 & left & 5.70 & 5.89 & di1 & & & \\
\hline I2 & right & 5.82 & I2 & left & 6.36 & 6.24 & di2 & & & \\
\hline $\mathrm{C}$ & right & 6.20 & $\mathrm{C}$ & left & 7.57 & 8.12 & $\mathrm{dc}$ & & & \\
\hline P1 & right & 7.77 & P1 & left & 7.05 & 8.04 & $\mathrm{dm} 1$ & left & 7.73 & 6.69 \\
\hline P2 & & & P2 & & & & $\operatorname{dm} 2$ & left & 10.64 & 8.93 \\
\hline M1 & & & M1 & left & 12.61 & 11.04 & M1 & left & 11.76 & 10.49 \\
\hline M2 & & & M2 & left & 11.37 & 10.18 & & & & \\
\hline
\end{tabular}

Table 6. Scores of Nonmetric Traits for the Aonae Dune Dentition: Criteria of Classification According to ASU System (Turner et al. i99i) for Permanent Teeth and "D" Series (Hanihara i96i) for Deciduous Teeth

\begin{tabular}{|c|c|c|c|c|c|c|c|c|c|}
\hline \multirow{2}{*}{$\begin{array}{l}\text { PERMANENT } \\
\text { TEETH } \\
\text { Trait }\end{array}$} & \multicolumn{3}{|c|}{$\begin{array}{l}\text { SKELETON } \\
\text { NO. I }\end{array}$} & \multicolumn{2}{|c|}{$\begin{array}{l}\text { SKELETON } \\
\text { NO. } 2\end{array}$} & \multirow{3}{*}{\begin{tabular}{l}
\multicolumn{1}{c}{$\begin{array}{c}\text { DECIDUOUS } \\
\text { TEETH }\end{array}$} \\
Trait \\
Shoveling
\end{tabular}} & \multicolumn{3}{|c|}{$\begin{array}{l}\text { SKELETON } \\
\text { NO. } 3\end{array}$} \\
\hline & Tooth & Side & Score & Side & Score & & Tooth & Side & Score \\
\hline Winging & UI1 & both & 3 & - & - & & dui1 & - & - \\
\hline Shoveling & UI1 & - & - & left & 3 & Shoveling & dui2 & - & - \\
\hline Shoveling & UI2 & left & 3 & right & 4 & Shoveling & duc & left & 1 \\
\hline Double shoveling & UI1 & - & - & left & 1 & Shoveling & dlc & - & - \\
\hline Double shoveling & UI2 & left & 0 & right & 1 & Crown pattern & dum1 & left & 2 \\
\hline Peg-shaped incisor & UI2 & left & 0 & right & 0 & Crown pattern & $\operatorname{dum} 2$ & left & 4 \\
\hline Root number & UP1 & right & 2 & left & 0 & Carabelli's trait & $\operatorname{dum} 2$ & left & 0 \\
\hline Hypocone & UM2 & right & 2 & left & 0 & Protostylid & $\mathrm{d} \operatorname{lm} 2$ & left & 3 \\
\hline Cusp 5 & UM1 & - & - & - & - & $\begin{array}{l}\text { Central ridge } \\
\text { of metd. }\end{array}$ & $\mathrm{d} \operatorname{lm} 2$ & left & 1 \\
\hline Carabelli's trait & UM1 & - & - & left & 4 & $7^{\text {th }}$ cusp & $\mathrm{d} \operatorname{lm} 2$ & left & 0 \\
\hline Enamel extension & UM2 & right & 0 & left & 0 & $\begin{array}{l}\text { Distal trigonid } \\
\text { crest }\end{array}$ & $\operatorname{dlm} 2$ & left & 0 \\
\hline Root number & LP1 & left & 1 & & & & & & \\
\hline Groove pattern & LM2 & - & - & left & + & & & & \\
\hline Cusp number & LM2 & - & - & left & 5 & & & & \\
\hline Protostylid & LM1 & - & - & left & 1 & & & & \\
\hline Cusp 5 & LM2 & - & - & left & 1 & & & & \\
\hline Cusp 6 & LM1 & - & - & left & 3 & & & & \\
\hline Cusp 7 & LM1 & - & - & left & 0 & & & & \\
\hline Root number & LM1 & right & 2 & - & - & & & & \\
\hline Root number & LM2 & right & 2 & - & - & & & & \\
\hline
\end{tabular}


very fragile. The greater sciatic notch displays an obtuse angle, indicating that this individual was a female. As with the upper body, the overall outlines of the lower limbs were observed during excavation, but only parts of the shafts could be reconstructed in the laboratory. The approximate maximum length of the right femur was measured at $410 \mathrm{~mm}$ before the burial was removed from the trench. Using this femoral length, the stature was estimated at $152.9 \mathrm{~cm}$. The femoral and tibial shafts are very slender. The right femoral midshaft sagittal diameter is $21 \mathrm{~mm}$ and the transverse diameter $29 \mathrm{~mm}$. The right tibial midshaft sagittal diameter is $26 \mathrm{~mm}$ and the transverse diameter $15 \mathrm{~mm}$. However, the femurs have marked linea aspera, suggesting that this individual had relatively well-developed hamstring muscles despite the slender lower limbs. The cross-section of the tibia is quite flat and similar to Ainu and Epi-Jömon samples.

\section{Skeleton No. 2}

Only the cranium was preserved incompletely. This skeleton is of a child of 11 years \pm 30 months, as estimated by the eruption of the deciduous and permanent teeth (Fig. 5a). The calvaria and alveolar processes of the upper and lower jaws were well preserved, but the facial skeleton had been destroyed. The remaining teeth are shown in Table 3. All the permanent dentition has erupted except for the second and third molars. The maxillary second deciduous molars are still retained. The crown surfaces of these deciduous second molars are heavily worn (Broca's third grade). As for the permanent dentition, the crown surfaces of the central incisors and first molars are slightly worn (Broca's first grade), but none of the other crowns display any wear.

For the permanent dentition of this individual, 18 nonmetric traits are scored as given in Table 6. The maxillary incisors and canines show a semi-shovel shape. The maxillary first molars have slightly developed Carabelli's traits, forming large $\mathrm{Y}$-shaped depressions. The distal lingual hypocone cusp is absent on the maxillary second molars. The sixth cusp is present in the mandibular first molars.
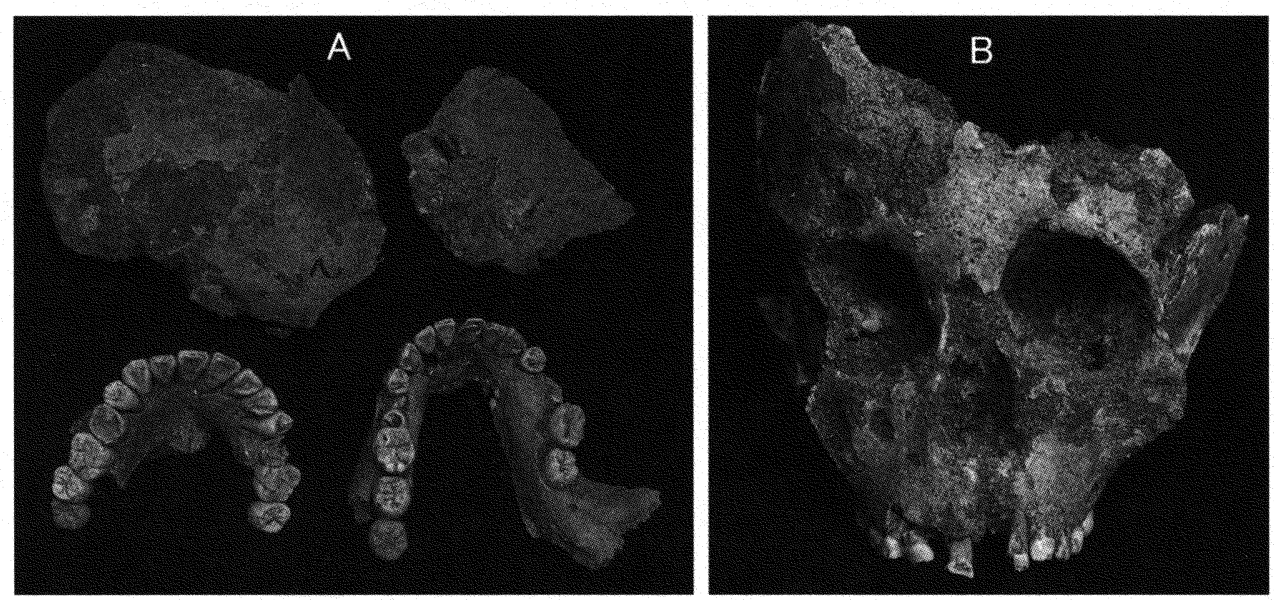

Fig. 5. The cranium and dentition of the Aonae Dune No. 2 (A) and No. $3(B)$ children. 
The lower second molars have hypoconulid distal cusps and plus-type groove patterns.

Neither dental caries nor calculus is observed on any tooth. Linear enamel hypoplasia is visible on the canines and first premolars. The lines on the mandibular teeth are not particularly clear, but single, wide, linear grooves are present in the maxillary teeth (groove width of $0.8 \mathrm{~mm}$ located $2.5 \mathrm{~mm}$ above the cervical lines of the canines, groove width of $0.5 \mathrm{~mm}$ located $1.9 \mathrm{~mm}$ above the cervical lines of the first premolars). It is generally argued that enamel hypoplasia is caused by malnutrition or illness in childhood (Goodman and Armelagos 1988). Taking the development timings of these tooth crowns into consideration, this individual might have experienced specific nutritional deficiency between four and five years of age.

The crown diameters of all the teeth (see Table 5) are large and, whatever the population affinity of this skeleton, there is a high probability that it is a male. A sex discrimination analysis performed using crown measurements of Hokkaido Ainu and protohistoric Kofun Japanese resulted in a more than 98 percent probability that Skeleton No. 2 is a male (Table 7).

\section{Skeleton No. 3}

The dental age estimates suggest this individual is a child of about 6 years \pm 24 months. Only the cranium was preserved (Fig. 5a). The calvaria and facial skeleton were well preserved, but the mandible was crushed into small fragments. The

Table 7. Discriminant Function Analysis Based on Dental Crown Diameters of Ainu and Kofun Japanese for Sexing the Aonae Dune Skeleton No. 2

\begin{tabular}{|c|c|c|c|c|c|}
\hline \multicolumn{3}{|c|}{ BASED ON AINU DATA } & \multicolumn{3}{|c|}{ BASED ON KOFUN DATA } \\
\hline \multicolumn{2}{|c|}{ Tooth diameter } & \multirow{2}{*}{$\frac{\text { Coefficient }}{2.689}$} & \multicolumn{2}{|c|}{ Tooth diameter } & \multirow{2}{*}{$\frac{\text { Coefficient }}{2.426}$} \\
\hline $\mathrm{BL}$ & LC & & $\mathrm{BL}$ & LP1 & \\
\hline BL & LP1 & -5.483 & MD & LM1 & 1.463 \\
\hline MD & UM1 & 3.156 & MD & $\mathrm{UC}$ & -3.015 \\
\hline MD & LC & 5.841 & MD & LC & 1.140 \\
\hline BL & UC & 1.264 & MD & UM2 & -1.321 \\
\hline $\mathrm{BL}$ & LM1 & -2.910 & BL & UM2 & 0.955 \\
\hline BL & UP1 & 2.917 & & & \\
\hline MD & UP1 & -2.097 & & & \\
\hline MD & UC & -1.922 & & & \\
\hline Const & & -24.382 & Cons & & -18.903 \\
\hline \multicolumn{3}{|c|}{ Sample size } & \multicolumn{3}{|c|}{ Sample size } \\
\hline & Males & 24 & & Males & 30 \\
\hline & Females & 17 & & Females & 22 \\
\hline Rate & ction & $97.6 \%$ & Rate & ction & $84.6 \%$ \\
\hline \multicolumn{3}{|c|}{ For Aonae Dune No. 2} & \multicolumn{3}{|c|}{ For Aonae Dune No. 2} \\
\hline Funct & & 7.12 & Funct & & 2.01 \\
\hline Sexin & & Male & Sexin & & Male \\
\hline \multicolumn{3}{|c|}{ (Accuracy 99.9\%) } & \multicolumn{3}{|c|}{ (Accuracy 98.9\%) } \\
\hline
\end{tabular}

MD: mesiodistal, BL: buccolingual, U: upper, L: lower. 


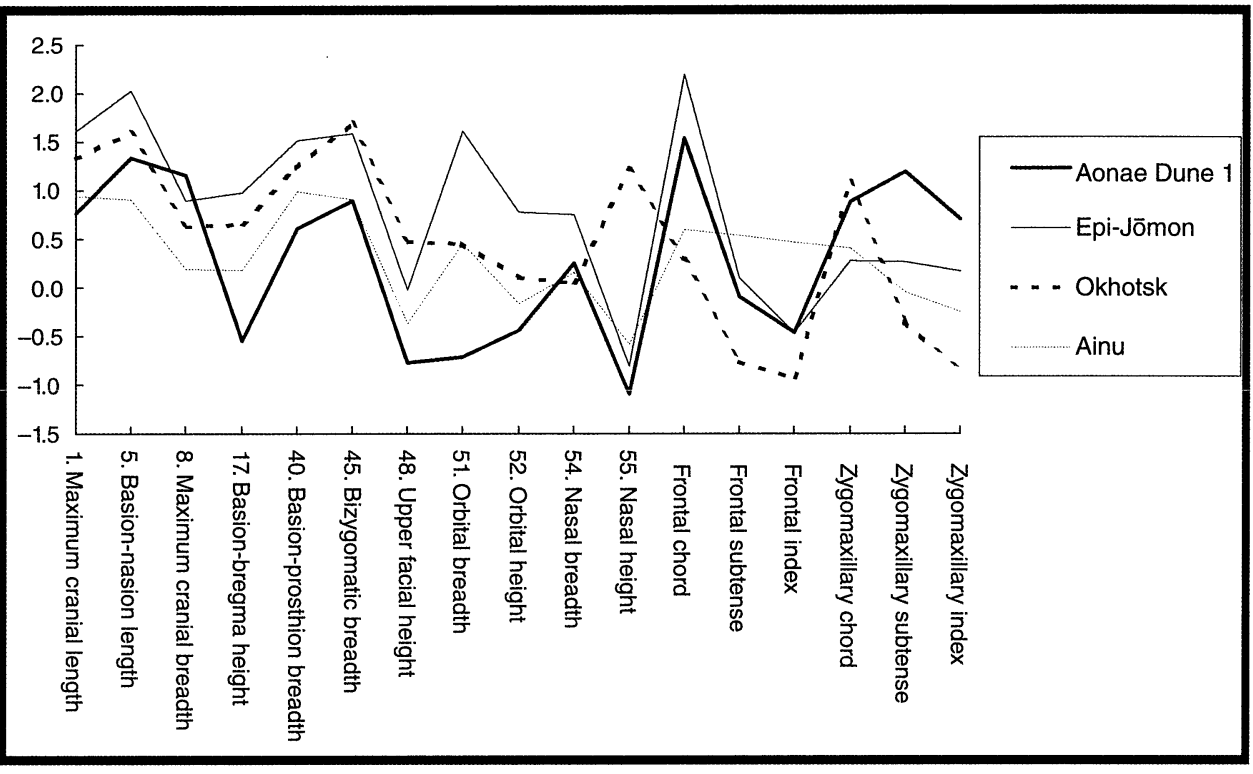

Fig. 6. Deviation diagram from modern Japanese females based on 18 cranial measurements of Skeleton No. 1.

orbital openings show a round shape, but the orbital height is relatively low. The teeth shown in Table 3 were preserved in the jaws. All deciduous teeth are present and both the maxillary and mandibular permanent first molars are erupted. From this dentition, age was estimated at about 6 years. Sex discrimination is difficult using only the deciduous teeth, and since the first molars are the only permanent teeth present, it was not possible to estimate the sex of this skeleton. The crown diameters of both the deciduous and permanent dentition are given in Table 5. Eight nonmetric dental traits were scored as shown in Table 6. In the mandibular second deciduous molars, the protostylid is weakly developed, forming a faint secondary groove.

\section{BIODISTANCE ANALYSIS}

\section{Cranial Measurements}

Figure 6 is a deviation diagram from 17 cranial measurements of modern Japanese females (Morita 1950). The diagram confirms our initial observations regarding the small size of the Aonae Dune No. 1 skull; the cranium is, in fact, smaller than the Ainu and Epi-Jōmon samples. Okhotsk people are characterized by high nasal openings and extremely flat faces as estimated by low facial flatness indices, including the frontal index (frontal subtense/chord) and the zygomaxillary index (zygomaxillary subtense/chord). From these points, it is clear that Aonae Dune No. 1 differs from other known Hokkaido Okhotsk populations and is similar to the Epi-Jōmon and Ainu, who have low nasal heights and rugged faces. This finding is consistent with the gross morphological observations described above suggesting that this skull has few Okhotsk features. 
Table 8. Penrose's Shape Distance $\left(\mathrm{C}_{z}{ }^{2}\right)$ and Distance $(\mathrm{I}-\mathrm{r})$ Transformed from Q-Mode Correlation Coefficient (r) from the Aonae Dune Skeleton No. i, Based on is Cranial Measurements

\begin{tabular}{lcc}
\hline & $\mathrm{C}_{\mathrm{z}}{ }^{2}$ & $\mathrm{I}-\mathrm{r}$ \\
\hline Ainu & 0.478 & 0.388 \\
Epi-Jōmon & 0.656 & 0.443 \\
Okhotsk & 1.046 & 0.821 \\
Kofun & 0.812 & 1.414 \\
\hline
\end{tabular}

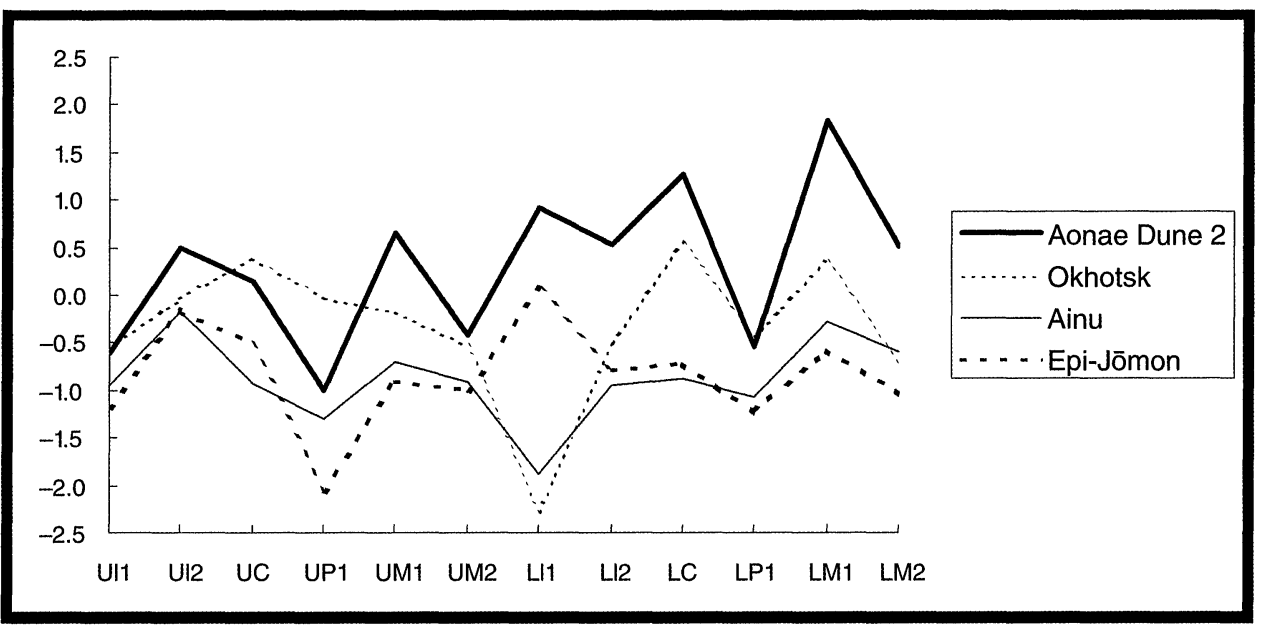

Fig. 7. Deviation diagram from modern Japanese males based on 12 mesiodistal crown diameters of the permanent teeth of Skeleton No. 2 (U: upper, L: lower).

Next, the cranial affinities between Aonae Dune No. 1 and the comparative samples were evaluated by calculating biological distances based on the above metric data. Penrose's shape distances and Q-mode correlation coefficients were computed between the samples, using the 15 cranial measurements (maximum cranial length, basion-nasion length, maximum cranial breadth, basion-bregma height, basion-prosthion breadth, bizygomatic breadth, upper facial height, orbital breadth, orbital height, nasal breadth, nasal height, frontal chord, frontal subtense, zygomaxillary chord, and zygomaxillary subtense). The results are given in Table 8. Both the Penrose's shape distances and distances $(1-r)$ transformed from the $\mathrm{Q}$-mode correlation coefficients $(\mathrm{r})$ indicate that the Hokkaido Ainu are the closest to Aonae Dune No. 1, followed next by the Epi-Jōmon people. The Okhotsk and Kanto Kofun Japanese are clearly distant from the Aonae Dune specimen.

\section{Tooth Crown Measurements}

For comparison of the Aonae Dune No. 2 child, 12 mesiodistal crown diameters of permanent teeth were used. Figure 7 is a deviation diagram of these measure- 
Table 9. Penrose's Shape Distance $\left(\mathrm{C}_{z}{ }^{2}\right)$ and Distance $(\mathrm{I}-\mathrm{r})$ Transformed from Q-Mode Correlation Coefficient (r) from the Aonae Dune Skeleton No. 2, Based on i 2 Mesiodistal Crown Diameters

\begin{tabular}{lcr}
\hline & $\mathrm{C}_{\mathrm{z}}{ }^{2}$ & $\mathrm{I}-\mathrm{r}$ \\
\hline Ainu & 0.656 & 0.672 \\
Epi-Jōmon & 0.376 & 0.318 \\
Okhotsk & 1.138 & 0.908 \\
Kofun & 0.918 & 1.523 \\
\hline
\end{tabular}

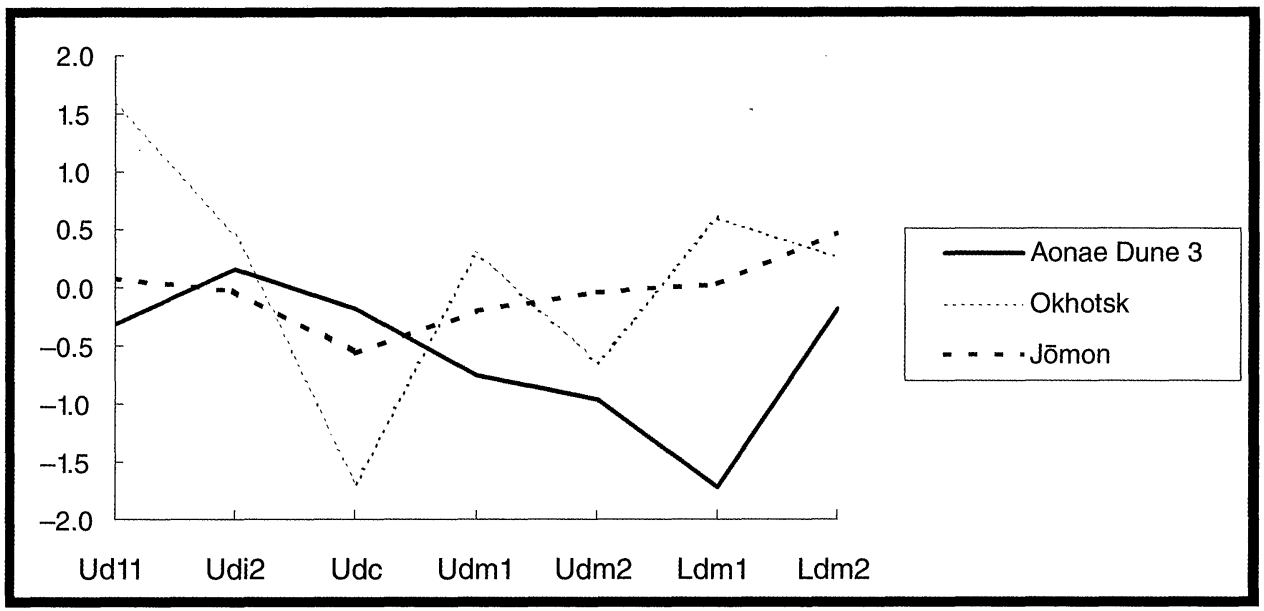

Fig. 8. Deviation diagram from modern Japanese males based on seven mesiodistal crown diameters of deciduous teeth of Skeleton No. 3 (U: upper, L: lower).

ment data, using modern Japanese males as the basis of comparison. Overall tooth size is smaller than any comparative population sample, and the deviation pattern of Aonae Dune No. 2 is similar to that of Epi-Jōmon populations.

The results of the Penrose's shape distance analysis and distance estimations by Q-mode correlation coefficients using the same 12 measurements are given in Table 9. These distance computations demonstrate that the Epi-Jōmon people are the closest to Aonae Dune No. 2, followed by the Ainu; the Okhotsk and Kanto Kofun populations are distant.

Figure 8 is a deviation diagram of seven mesiodistal crown diameters of the deciduous teeth of the Aonae Dune No. 3 child. The deviation pattern of Aonae Dune No. 3 shows apparent dissimilarity with the Okhotsk sample as compared with the Jōmon people, although the deviation pattern is not identical to that of the Jōmon sample.

In the distance analyses, data from Kofun populations (Kitagawa et al. 2002) were added for comparison. The results of computation of Penrose's shape distances and distances of Q-mode correlation coefficients, using the same seven deciduous diameters, are given in Table 10. The Penrose's shape distances indicate that Aonae Dune No. 3 is closest to the Jōmon sample and is far distant from the 
Table io. Penrose's Shape Distance $\left(\mathrm{C}_{\mathrm{z}}{ }^{2}\right)$ and Distance $(\mathrm{I}-\mathrm{r}$ ) Transformed from Q-Mode Correlation Coefficient (r) from the Aonae Dune Skeleton No. 3 , Based on 7 Mesiodistal Crown Diameters of Deciduous Teeth

\begin{tabular}{lcc}
\hline & $\mathrm{C}_{\mathrm{z}}{ }^{2}$ & $\mathrm{I}-\mathrm{r}$ \\
\hline Okhotsk & 1.574 & 1.076 \\
Jömon & 0.508 & 1.015 \\
Kofun & 0.785 & 1.679 \\
\hline
\end{tabular}

Okhotsk sample. The Q-mode correlation distances place Aonae Dune No. 3 closest to the Jōmon sample, although the distance to the Okhotsk sample is similar to that from the Jomon people. The difference from the Kofun population is evident in both the Penrose's shape distances and the Q-mode correlation coefficients.

\section{DISCUSSION}

All three skeletons from the Aonae Dune site analyzed here display few morphological features characteristic of the people of the Okhotsk culture, and they are also different from contemporary Kofun-period populations of Honshu. Similarities with Epi-Jōmon and Ainu populations of Hokkaido are, however, clearer. The scarcity of human skeletal remains from the Satsumon period means that it is not possible to compare the Aonae Dune skeletons directly with Satsumon samples. As the Satsumon people are widely thought to be an intermediate stage between the Epi-Jōmon and Ainu, however, the similarity of the Aonae Dune remains to Epi-Jōmon samples suggests that they were indeed close to the Satsumon people. The grave goods associated with Aonae Dune No. 1 imply that the social identity of that female had become associated with what we know archaeologically as the Okhotsk culture. The interpretation of the Aonae Dune No. 2 and No. 3 children is more difficult since, as noted, the arrangement of pounding stones in this burial appears to be related to an Epi-Jomon custom. At the same time, however, the fact that these children were buried in an Okhotsk pit building suggests a mortuary ritual within the context of Okhotsk culture.

Two interpretations of the results of the biodistance analyses conducted here are possible. Since at present all of the human remains from Aonae appear to be of Epi-Jōmon/Satsumon ancestry, one possibility is that the inhabitants of this site were individuals from that tradition who had adopted many aspects of Okhotsk culture. Such an interpretation might be consistent with the unusual location of the Aonae Dune site outside of the main area of Okhotsk settlement. As the site has so far only produced three individuals, however, we can only speculate as to the biological identity of the other inhabitants. We therefore regard it as more likely that the skeletons analyzed here represent three Epi-Jōmon/Satsumon individuals who were adopted-whether voluntarily or otherwise-into Okhotsk society and that other more typically Okhotsk skeletal remains will be discovered at Aonae in the future.

As mentioned, the Aonae Dune site is located outside the main area of Okhotsk settlement in Hokkaido, which was the northern and eastern coastal fringes of 
TABle i i. Seasonal Indicators from Aonae

(IDENTIFICATIONS FROM KaneKo AND DOI 2003)

\begin{tabular}{lll}
\hline SEASON & \multicolumn{1}{c}{ RESOURCE } & PRESENCE/QUANTITY (NISP/FRAGMENTS) \\
\hline Early spring & Herring (Clupeidae), Akta mackerel & Herring: Very rare (25); Akta \\
Spring-autumn & (Pleurogrammus ozonus) & mackerel: absent \\
& Abalone (Haliotidae discus), sea & Abalone: Common (374); sea urchin: \\
Autumn & Salmonidae & common (9973) \\
& Cod (Gadidae) & Rare (125) (accumulation as winter \\
Midwinter & food unlikely)
\end{tabular}

NISP: Number of identified specimens.

that island (see Fig. 1). The Japan Sea coastline of Hokkaido and northern Honshu would no doubt have been an attractive environment for intrusive Okhotsk populations from Sakhalin, but extensive settlement by Epi-Jōmon and Satsumon groups probably made it harder to exploit than the sparsely settled northeastern Sea of Okhotsk coastline. At the same time, however, Aonae is one of a number of sites on the Sea of Japan coast of Hokkaido that have produced Okhotsk remains. At Aonae, the presence of pit houses, Haji and Satsumon pottery, a jasper bead, and Hokkaido obsidian suggests that the site was inhabited for a significant length of time, perhaps for the purpose of trade. Twenty-nine bird, fish, and mammal taxa have been reported from Aonae (Kaneko and Doi 2003:60), a number that is close to the average of ten other Okhotsk sites (31.5 taxa, range 19-38, SD 5.8) tabulated by Hudson (2005). Seasonal indicators suggest the site was occupied from the spring to late autumn, but there is little evidence for winter occupation (Table 11). A contrastive case with the Aonae Dune site is found at Chatsu 4, located on the Shakotan Peninsula of mainland Hokkaido (see Fig. 1), approximately $100 \mathrm{~km}$ north of Aonae, where morphologically Okhotsk skeletons were unearthed despite association with Epi-Jōmon cultural remains (Matsumura 2001). This finding suggests that interaction between the Okhotsk and surrounding cultures had already begun by the Epi-Jōmon period.

Documentary evidence from Japan indicates that Northeast Asian groups were exploiting the islands of the Sea of Japan on a seasonal basis. In the entry for Kimmei 6/12 (A.D. 544), for example, the Nihon Shoki records: "The following report was received from the province of Koshi: 'At Cape Minabe [Sado Island], there arrived men of Su-shen in a boat, and staid [sic] there. During the spring and summer they caught fish, which they used for food. The men of that island ... called them devils, and did not dare go near them'" (Aston 1972:II, 58). "Su-shen" is an anachronistic term for the Mohe, a Tungusic people of the Amur. Although many scholars link the Okhotsk with non-Tungusic groups such as the later Nivkh (e.g., Kikuchi 1978), in the Nihon Shoki "Su-shen" may have been used as a literary term for Manchurian peoples, and it is by no means impossible that it refers to the people of the Okhotsk culture. Although no Okhotsk sites are known as far south as Sado, there is no archaeological evidence for the settlement of a Northeast Asian people other than the Okhotsk down the northern Sea of Japan coast. Whatever the exact relationship between the 
Okhotsk and the "Su-shen," the exploitation of the Aonae Dune site probably followed a similar pattern to that described in the Nihon Shoki-but with the major difference that close interaction and possibly intermarriage had already occurred between the Okhotsk people and their neighbors.

\section{Adoption, Reticulation, and Ethnogenesis}

The ethnogenesis of non-Japanese peoples in medieval Hokkaido is enormously complex. In a sense, this article has increased that complexity without appreciably furthering our understanding of its causes. In this context, however, we wish to make some final points regarding the nature of this ethnic complexity. For some anthropologists, the type of ethnic complexity or "reticulation" described here is not just normal -it is regarded as the most important aspect of the process of ethnogenesis (Moore 1994a, 1994b, 2001). John Moore's (1987) work on intermarriage and "hybrid bands" amongst the Cheyenne certainly provides possible comparative material for understanding the Okushiri Okhotsk. At the same time, however, this does not mean that cladistic processes can be "rejected" as Moore (2001:52) suggests. As noted a decade ago by Peter Bellwood (1996), the question of scale is crucial: At the micro level of the individual, reticulate models are often the most appropriate, but branching processes can still be important at the macro scale-although such branches never evolve completely independently for very long. The use of the term "cladistic" in debates over ethnogenesis is thus confusing, but the Okhotsk shows the importance of both branching and reticulate processes.

The origins of the Okhotsk appear to lie in the Amur region of the Russian Far East, from where the culture spread to Sakhalin and then Hokkaido and the Kuril Islands. Iron Age groups from the Amur branched both north and south into the circum-Sea of Okhostk region. Archaeologically, Yamaura (1998) associates these movements with the Tokarev and Okhotsk cultures respectively, although some controversy remains over the dating of the Tokarev culture. The end of the Okhotsk culture in Hokkaido was very different in the northern and eastern parts of that island (Ohyi 1975). The Okhotsk population of the Tobinitai phase of eastern Hokkaido was gradually incorporated into Satsumon culture (Onishi 2003), but in northern Hokkaido the Okhotsk people appear to have moved back to Sakhalin.

We do not doubt that reticulate processes of adoption and intermarriage were important in prehistoric societies, but the complexity of ethnic constructions does not make such ethnic units any less real to their members. As noted above, Nivkh clan organization appears to have been quite flexible in embracing adopted newcomers (Shternberg 1999:156), but the broad ethnic identity of the Nivkh continued in spite of - or perhaps because of - such flexibility. In her monograph on the complex formation of the Choctaw people, Galloway (1995:4) similarly notes that "the Choctaws have undergone as much change from prehistory to the present as any other native group of the Southeast [United States] but have simultaneously retained the Choctaw language and cultural practices with a success that cannot be explained if their culture had no particular substance of its own." Having written two books on the Cheyenne, even John Moore $(1987,1996)$ appears not to doubt that such a tribe exists! Much recent work on ethnogenesis has 
stressed the role of identity formation within changing structures of economic and political domination (e.g., Hill 1996; Hudson 1999:175-232; Patterson 1987). Moore's fascinating work on the Cheyenne has also shown that their flexible marriage patterns developed within quite specific historical contexts. Future work on the Okhotsk and medieval Hokkaido needs to consider further the connections between ethnic and historical change with the same degree of sophistication shown in Moore's work on the ethnogenesis of the Plains Indians.

\section{CONCLUSION}

Excavations at the Aonae Dune site on Okushiri Island, Hokkaido, produced human skeletal remains from three individuals. Although these individuals apparently derive from Okhotsk culture contexts, their skeletal morphology is rather different from most other known Okhotsk culture skeletal remains. One possible interpretation of these remains is that they were people of Epi-Jōmon/Satsumon ancestry who were adopted into Okhotsk society. The research reported here provides further support for the point made by Hudson (1999) that detailed biodistance analyses of prehistoric human skeletons are an invaluable component of the archaeology of ethnicity since they enable us to compare the biological and cultural components of human identities. This does not mean, however, that ethnicity can be "reduced" to biology. Cases such as that described here, where biology and culture clearly do not overlap, call for a nuanced explanation that takes full account of the complex historical processes of cultural reticulation that occur in all societies.

\section{ACKNOWLEDGMENTS}

We wish to thank Miriam Stark and the three anonymous reviewers for their detailed comments on an earlier version of this article.

\section{NOTE}

1. We have no information regarding the language(s) spoken by the people of the Okhotsk culture. Given that the Okhotsk was intrusive in Hokkaido and remained largely separate from other cultures there, it seems a reasonable assumption that it possessed a language or languages that were different from those spoken by the people of the Epi-Jomon and Satsumon traditions. These latter groups probably spoke languages ancestral or closely related to Ainu. That Ainu appears to contain few borrowings from languages other than Japanese (Vovin 1993) suggests that the Okhotsk people had little linguistic influence on the Epi-Jōmon or Satsumon traditions.

\section{REFERENCES}

Aston, W. G. (Trans.)

1972 Nihongi: Chronicles of Japan from the Earliest Times to A.D. 697. Rutland, VT and Tokyo: Tuttle.

Batten, Bruce L.

2003 To the Ends of Japan: Premodern Frontiers, Boundaries, and Interactions. Honolulu: University of Hawai'i Press.

BELlWOOD, P.

1996 Phylogeny vs. reticulation in prehistory. Antiquity 70: 881-890. 
Bellwood, P., ANd C. Renfrew, eds.

2003 Examining the Farming/Language Dispersal Hypothesis. Cambridge: McDonald Institute for Archaeological Research.

DeVos, G.

1982 Ethnic pluralism: Conflict and accommodation, in Ethnic Identity: Cultural Continuities and Change: 5-41, ed. G. DeVos and L. Romanucci-Ross. Chicago: University of Chicago Press.

Dodo, Y., AND Y. KawaKubo

2002 Cranial affinities of the Epi-Jomon inhabitants in Hokkaido, Japan. Anthropological Science $110: 1-32$

Dolukhanov, P. M.

2003 Archaeology and languages in prehistoric northern Eurasia. Japan Review 15:175-186.

EMBERLING, G.

1997 Ethnicity in complex societies: Archaeological perspectives. Journal of Archaeological Research $5: 295-344$.

Evison, M. P.

2001 Contexts of change in Holocene Britain: Genes, language, and archaeology, in Archaeology, Language and History: Essays on Culture and Ethnicity: 173-198, ed. J. E. Terrell. Westport, CT: Bergin and Garvey.

FujII, AKIRA

1960 On the relation of long bone lengths of limbs to stature. Bulletin of the School of Physical Education, Juntendo University 3:49-61 (in Japanese).

\section{Galloway, Patricia}

1995 Choctaw Genesis, 1500-1700. Lincoln: University of Nebraska Press.

Goodman, A. H., and G. J. Armelagos

1988 Childhood stress and decreased longevity in a prehistoric population. American Anthropologist 90:936-944.

Hall, M., U. Maeda, and M. J. Hudson

2002 Pottery production on Rishiri Island, Japan: Perspectives from X-ray fluorescence studies. Archaeometry $44: 213-228$.

Hanihara, Kazuro

1961 Criteria for classification of crown characters of the human deciduous dentition. Journal of the Anthropological Society of Nippon 69:27-45.

1998 Nihonjin no Hone to Roots [The Skeletons and Roots of the Japanese]. Tokyo: Kadokawa.

Hill, J. D., ED.

1996 History, Power, and Identity: Ethnogenesis in the Americas, 1492-1992. Iowa City: University of Iowa Press.

Hokkaido Prefectural Archaeological Operations Center, eds.

2002 Okushiri-chō Aonae Sakkȳu Iseki [The Aonae Dune Site]. Ebetsu: Hokkaido Prefectural Archaeological Operations Center.

2003 Okushiri-chō Aonae Sakkyū Iseki 2 [The Aonae Dune Site 2]. Ebetsu: Hokkaido Prefectural Archaeological Operations Center.

Hudson, MARK J.

1999 Ruins of Identity: Ethnogenesis in the Japanese Islands. Honolulu: University of Hawai'i Press.

2004 The perverse realities of change: World system incorporation and the Okhotsk culture of Hokkaido. Journal of Anthropological Archaeology $23: 290-308$.

2005 Diet breadth and life history in the Okhotsk: A preliminary comparison of north and east Hokkaido, in Umi to Kōkogaku [Maritime Archaeology]: 243-249, ed. Society for Study of Maritime Archaeology. Tokyo: Rokuichi Shobo.

ISHIDA, HAJIME

1988 Morphological studies of Okhotsk crania from Omisaki, Hokkaido. Journal of the Anthropological Society of Nippon 96:17-46.

1994 Skeletal morphology of the Okhotsk people on Sakhalin island. Anthropological Science $102: 257-269$. 
Ishida, Hajime, and TsunehiKo Hanihara

1992 Shutsudo jinkotsu no bunseki [Analysis of human remains], in Archaeological Investigation at Hamanaka II, Rebun Island, Hokkaido: 89-107, ed. Rebun-chō Board of Education. Rebun-chō: Rebun-chō Board of Education.

JONES, S.

1997 The Archaeology of Ethnicity: Constructing Identities in the Past and Present. London: Routledge.

KANEKo, H., AND K. DoI

2003 Okushiri-chō Aonae sakkyū iseki no dōbutsu itai [Faunal remains from the Aonae Dune site, Okushiri-chō], in Okushiri-chō Aonae Sakkyū Iseki 2 [The Aonae Dune Site 2]: 5973, ed. Hokkaido Prefectural Archaeological Operations Center. Ebetsu: Hokkaido Prefectural Archaeological Operations Center.

KikUChI, Tosнiнiко

1978 Ohötsuku bunka no kigen to shūhen shobunka to no kanren [The origins of the Okhotsk culture and relations with various surrounding cultures]. Hoppō Bunka Kenkȳ̄ 12:39-74.

Kirch, Patrick V., and Roger C. Green

2001 Hawaiki, Ancestral Polynesia: An Essay in Historical Anthropology. Cambridge: Cambridge University Press.

Kitagawa, Y., Y. Manabe, J. Oyamada, and A. Rokutanda

2002 Japanese deciduous tooth size: Past and present. Anthropological Science 110:335-347.

Koganei, Y.

1893 Beiträge zur physischen Anthropologie der Aino. Mitteilungen der Medizin Fakultät Universität Tokio $2: 1-249$.

MAEDA, UsHiO

2002 Ohōtsuku no Kōkogaku [The Archaeology of the Okhotsk]. Tokyo: Dōseisha.

Martin, R., and K. Saller

1957 Lehrbuch der Anthropologie, Band 1. Stuttgart: G. Fischer.

\section{Matsumura, Hirofumi}

1989 Geographical variation of dental measurements in the Jomon population. Journal of the Anthropological Society of Nippon $97: 493-512$.

1990 Geographical variation of dental characteristics in the Japanese of the Protohistoric Kofun period. Journal of the Anthropological Society of Nippon 98:439-449.

1991 Deciduous tooth size in the prehistoric Jomon and Yayoi peoples of Japan. Bulletin of the National Science Museum, Tokyo D17:21-29.

1993 Affinities of the Kurile Ainu and the Okhotsk cultural people as viewed from tooth crown measurements. Memoirs of the National Science Museum, Tokyo D26:171-175.

1994 A microevolutional history of Japanese people from dental characteristics perspective. $A n$ thropological Science 102:93-118.

2001 Differentials of Yayoi immigration to Japan as derived from dental metrics. Homo $52: 135-156$.

MOORE, JoHN H.

1987 The Cheyenne Nation. Lincoln: University of Nebraska Press.

1994a Ethnogenetic theory. National Geographic Research and Exploration 10:11-23.

$1994 b$ Putting anthropology back together again: The ethnogenetic critique of cladistic theory. American Anthropologist 96:925-948.

1996 The Cheyenne. Oxford: Blackwell.

2001 Ethnogenetic patterns in native North America, in Archaeology, Language and History: Essays on Culture and Ethnicity: 31-56, ed. J. E. Terrell. Westport, CT: Bergin and Garvey.

Moorrees, C.F.A., And R. B. Reed

1954 Correlations among crown diameters of human teeth. Archives of Oral Biology 9:685-697.

Morita, S.

1950 Kantō chihō hito tōgaikotsu no jinruigakuteki kenkyū [Anthropological research on human crania from the Kanto region]. Jikei-Ikadaigaku Kaibōgaku Gyōsekishū 3:1-59.

OHYi, Haruo

1975 The Okhotsk culture, a maritime culture of the southern Okhotsk Sea region, in Prehistoric Maritime Adaptations of the Circumpolar Zone: 123-158, ed. W. Fitzhugh. The Hague: Mouton. 
ONISHI, H.

2004 Residents of a cultural boundary area: Lineage and household composition of the Tobinitai culture in northern Japan. Nihon Kökogaku 16:157-177 (in Japanese with English summary).

Ousley, STEPhen D.

2001 Lessons learned from the repatriation program at the National Museum of Natural History, Smithsonian Institution, in International Colloquium on the First Americans: 16-19, eds. M. Hudson and K. Omoto. Kyoto: International Research Center for Japanese Studies.

Patterson, Thomas C.

1987 Tribes, chiefdoms, and kingdoms in the Inca empire, in Power Relations and State Formation: 117-127, ed. T. C. Patterson and C. W. Gailey. Washington, DC: American Anthropological Association.

Penrose, L. S.

1954 Distance, size and shape. Annals of Eugenics 18:337-343.

Rose, J. C., T. J. Green, and V. D. Green

1996 NAGPRA is forever: Osteology and the repatriation of skeletons. Annual Review of Anthropology $25: 81-103$.

SHTERNBERG, L.

1999 The Social Organization of the Gilyak. New York: American Museum of Natural History.

SNeATh, P. H., ANd R. R. Sokal

1973 Numerical Taxonomy. San Francisco: W. H. Freeman and Co.

Terrell, John E., ED.

2001 Archaeology, Language and History: Essays on Culture and Ethnicity. Westport, CT: Bergin and Garvey.

Turner, C. G. II, C. Nichol, And G. Scott

1991 Scoring procedures for key morphological traits of the permanent dentition: The Arizona State University Dental Anthropology System, in Advances in Dental Anthropology: 13-31, eds. M. Kelly and C. S. Larsen. New York: Wiley-Liss.

UBELAKER, D. H.

1991 Human Skeletal Remains, Excavation, Analysis, Interpretaion. Washington, DC: Taraxacum.

Vovin, A.

1993 A Reconstruction of Proto-Ainu. Leiden: E. J. Brill.

YAMAgUCHI, BIN

1973 Facial flatness measurements of the Ainu and Japanese crania. Bulletin of the National Science Museum, Tokyo 16:161-171.

1974 Paleoantholopogy in Hokkaido. The Quaternary Research 12:257-264 (in Japanese with English title and summary).

1987 Metric study of the crania from protohistoric sites in eastern Japan. Bulletin of the National Science Museum, Tokyo D13:1-9.

Yamaura, KiYoshi

1998 The sea mammal hunting cultures of the Okhotsk Sea with special reference to Hokkaido prehistory. Arctic Anthropology 35 :321-334.

\section{ABSTRACT}

This article describes human skeletal remains from the Aonae Dune site, Okushiri Island, Hokkaido, Japan. Skeletal remains of an adult female and two subadults were excavated in 2002. Although these remains derived from Okhotsk culture contexts, analyses of cranial and tooth crown measurements demonstrated that Aonae Dune No. 1 (the adult female), Aonae Dune No. 2 (a child of about 11 years), and Aonae Dune No. 3 (a child of about 6 years) are morphologically closer to Epi-Jōmon or Jōmon and Ainu populations and significantly different from other Okhotsk samples in Hokkaido. It is argued that these three skeletons probably represent individuals from a different culture who were adopted into Okhotsk society. KeYwords: Hokkaido, Okhotsk culture, Aonae Dune site, osteological analyses, ethnicity. 